\title{
Effect of Erythropoietin on Granulocytopoiesis: In Vitro and in Vivo Studies in Weanling Rats
}

\author{
JOYCE M. KOENIG AND ROBERT D. CHRISTENSEN \\ Division of Human Development and Aging, University of Utah School of Medicine, Salt Lake City, Utah 84132
}

\begin{abstract}
In clonogenic assays, high concentrations of erythropoietin (epo) result in reduced generation of neutrophils from progenitors. Fetal progenitors appear to be more sensitive to this effect than are those of adults. Neutropenia has not been observed, however, as a complication of epo administration to anemic adults. Nevertheless, we remained concerned that diminutions in the neutrophil proliferative or storage pools might occur in epo-treated neonates. Therefore, after establishing that epo induces down-modulation of neutrophil generation in vitro from progenitors of weanling rats, we administered high doses of epo and subsequently performed neutrophil kinetic studies. Six pairs of 8-9-d-old rats were given three daily injections of $2000 \mathrm{IU} / \mathrm{kg}$ of either epo or a control. Fortyeight $h$ later, the epo recipients had elevations in reticulocytes, circulating normoblasts, and hematocrits, as well as in splenic and femoral normoblasts and mature erythroid progenitors. However, no changes were observed in concentrations of circulating neutrophils, monocytes, or lymphocytes. In addition, no changes were observed in the splenic or marrow neutrophil storage or proliferative pools, or the pools of granulocyte-macrophage progenitors or multipotent progenitors. Thus, although in vitro high concentrations of epo resulted in diminished generation of neutrophils from progenitors, no reductions were observed in vivo using epo doses 4 - to 40 -fold higher than those generally administered to humans. (Pediatr Res 27: 583587,1990 )
\end{abstract}

\section{Abbreviations}

epo, erythropoietin

BFU-E, erythroid burst-forming unit

CFU-E, erythroid colony-forming unit

CFU-GM, granulocyte-macrophage colony-forming unit

CFU-MIX, multipotential progenitors

NSP, neutrophil storage pool

NPP, neutrophil proliferative pool

SCM, spleen-conditioned medium

Epo is a humoral regulator of erythropoiesis $(1,2)$. Certain hyporegenerative anemias, such as the anemia of prematurity and the anemia of end-stage renal disease, are due to limited or defective production of epo (3-5). Administration of recombinant epo is an effective alternative to erythrocyte transfusion for patients with the anemia of end-stage renal disease (6-8), and has been proposed as an alternative to transfusion for patients with the anemia of prematurity $(3,4,9)$. Although epo admin-

Received November 9, 1989; accepted January 12, 1990.

Correspondence: Robert D. Christensen, M.D., Division of Human Development and Aging, University of Utah School of Medicine, 50 North Medical Drive, Salt Lake City, UT 84132

Supported by Grant HD-220830 from the National Institutes of Health. istration to anemic adults appears to be reasonably safe $(6-8$, $10)$, concerns have been published regarding its administration to preterm neonates $(11,12)$. One specific concern relates to the observation that, in vitro, epo down-modulates the production of neutrophils from fetal hematopoietic progenitors (12). If epo administration to neonates results in reduced neutrophil production, the effect on antibacterial defense, already significantly impaired in neonates (13), would require definition. Thus, our studies were performed to assess the effect of epo administration on granulocytopoiesis and neutrophilic pool sizes, using a weanling rat model.

\section{MATERIALS AND METHODS}

Animal injections. Sprague-Dawley rats with timed pregnancies (Charles River Laboratories, Stone Ridge, NY) were housed at the University of Utah vivarium, and given free access to water and rat food. After delivery, litters were culled to six to eight pups and housed with their mothers. Beginning on the 8th to 9th day of life, six pups received three consecutive daily s.c. injections of $2000 \mathrm{IU} / \mathrm{kg}$ recombinant human epo (Ultrapure Epo, >160000 IU/mg, Amgen, Thousand Oaks, CA). The epo was suspended in sterile PBS with $0.02 \%$ BSA (Sigma Chemical Co., St. Louis, MO). As a control, an additional six pups received the same volume of the PBS-albumin solution per injection. Animals were injected as paired sets (one epo and one control) because the neutrophil kinetic studies could be performed on a maximum of only two animals per day. All animals were killed by $\mathrm{CO}_{2}$ inhalation anesthesia $48 \mathrm{~h}$ after the 3rd injection. Blood samples were obtained by severing the external jugular vein, and the spleen and both femurs were removed.

Quantification of circulating, splenic, and myeloid pools of erythroid and granulocytic cells. Circulating concentrations of nucleated blood cells were determined electronically (Coulter Electronics, Hialeah, FL). Blood smears were stained with Wright's stain and subjected to 200-cell differential counts. Reticulocyte counts were performed on smears obtained from blood incubated with methylene blue, and were corrected to a hematocrit of $0.40 \mathrm{~L} / \mathrm{L}$. Hematocrits were determined by centrifugation of microcapillary tubes (Damon/IEC Division, Needham Heights, MA).

Marrow cells were obtained from the two femurs by flushing their contents with $5 \mathrm{~mL}$ of sterile $\alpha$-MEM (HyClone Laboratories, Logan, UT), as previously described (14). Electronic cell counts and 250-500 cell differential counts were made from the resulting suspensions. Spleen cells were obtained by mincing the organ with scissors and passing the pieces through serially smaller needles ranging from 19-gauge to 23-gauge. Electronic cell counts and smears were made from the resulting cell suspensions. The NSP in the spleen was defined as the total number of segmented neutrophils, band neutrophils, and metamyelocytes in the organ. The NSP of the entire skeletal marrow was estimated, as previously described (14), by multiplying the NSP in the combined femurs by nine, reflecting the fact that in 10-d-old rats, the combined femurs contain about $11 \%$ of the total skeletal marrow 
(15). The NPP in the spleen was defined as the total number of myeloblasts, promyelocytes, and myelocytes in the organ. The NPP of the entire skeletal marrow was estimated in the same way as the NSP.

Hematopoietic progenitor cell culture. Marrow and spleen cells were cultured in quadruplicate $35-\mathrm{mm}$ plastic tissue culture dishes in $\alpha$-MEM containing 1\% (1500 centipoise) methylcellulose (Fisher Scientific, Norcross, GA), 30\% FCS (HyClone), 1\% globulin-crystallized, deionized BSA (Sigma), and $5 \times 10^{-5} \mathrm{M}$ mercaptoethanol (Eastman Organic Chemicals, Rochester, NY). Cultures of CFU-E contained $10^{5}$ cells $/ \mathrm{mL}$ and, in the initial epo dose-response studies, concentrations of epo ranging from 0.0 to $1.0 \mathrm{IU} / \mathrm{mL}$. In subsequent studies of CFU-E, epo concentrations of $0.25 \mathrm{IU} / \mathrm{mL}$ were used. CFU-E were enumerated after $3 \mathrm{~d}$ in culture using an inverted microscope.

Cultures of early progenitors (CFU-MIX, CFU-GM, and BFUE) contained $0.5 \times 10^{5}$ cells $/ \mathrm{mL}$, and in the initial dose-response studies, contained concentrations of epo ranging from 0.0 to 4.0 $\mathrm{IU} / \mathrm{mL}$, and SCM concentrations ranging from 0 to $20 \%$. The SCM was prepared using previously described methods $(16,17)$. In subsequent studies of early progenitors, epo concentrations of $2.0 \mathrm{IU} / \mathrm{mL}$ and $\mathrm{SCM}$ concentrations of $10 \%$ were used. In studies of the effect of epo on CFU-GM colony formation and neutrophil generation in vitro, $10 \%$ SCM was used and the concentration of epo was varied $(0.0,0.1,1.0$, and $10.0 \mathrm{IU} / \mathrm{mL})$. As a control for these studies, epo that had been preneutralized (18) by incubation with antiepo antiserum (Terry Fox Laboratories, Vancouver, BC) was also tested. Early progenitors were scored after 7-9 d in culture. Colonies generated from BFU-E and from CFU-GM were identified in situ as described by Kimura et al. (19). Colonies generated by CFU-MIX were identified in situ by the presence of tightly clustered hemoglobinized cells plus loosely arranged nonhemoglobinized cells (20).

Data analysis. Statistics were performed using $t$ test or paired $t$ test, as applicable.

These studies were approved by the University of Utah Institutional Animal Care and Use Committee.

\section{RESULTS}

Hematocrits and reticulocyte concentrations during 1 st 4 wk of life. These studies were performed to select an age at which to begin epo injections in the young rats. Hematocrits and reticulocyte counts were measured in groups of at least five noninjected, apparently healthy rats at various ages, including $2 \mathrm{~d}$ preterm (delivered by hysterotomy), the 1 st d of life, and after 5 , $7,10,13,20$, and $28 \mathrm{~d}$. As shown in Figure 1, reticulocyte counts and hematocrits diminished over the first $10-15 \mathrm{~d}$ of life. We selected 8- to 9-d-old rats for the epo administration studies because their reticulocyte counts and hematocrits were falling, and thus any epo-induced erythropoiesis would be more evident.

Effect of epo on generation of granulocytes in vitro. These studies were performed to determine whether epo resulted in decreased CFU-GM colony formation and reduced neutrophil generation from the progenitors of normal weanling rats in vitro $(11,12)$. Light-density ( $\mathrm{sp}$ gr $<1.077)$ marrow cells, flushed from the femurs of 8- to 9-d-old rats, were cultured in various concentrations of epo, or in epo preneutralized by incubation with antiepo antiserum. As shown in Table 1, increasing concentrations of epo were associated with a diminution in CFU-GM colony formation, and with diminished neutrophil generation from hematopoietic progenitors.

Effect of epo administration on circulating cells. These studies were performed to determine whether the administration of high doses of epo to 8- to 9-d-old rats had an effect on their circulating concentrations of neutrophils. Figure 2 shows the reticulocytes, normoblasts, hematocrits, and the circulating concentrations of neutrophils, monocytes, and lymphocytes in the six pairs of weanling rats. In all cases, the reticulocyte counts, the concentrations of circulating normoblasts, and the hematocrits were higher
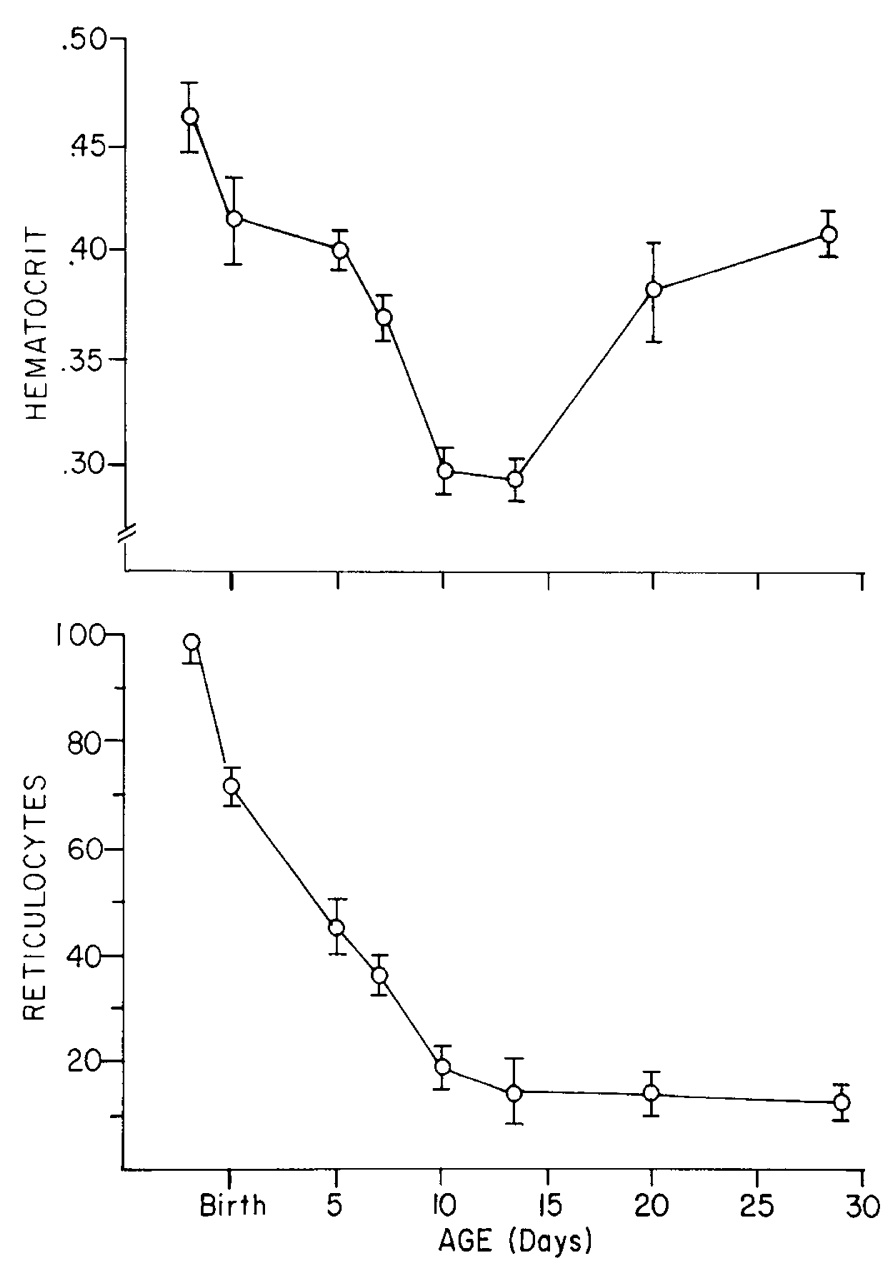

Fig. 1. Hematocrits and reticulocyte counts in normal rats during the 1 st $28 \mathrm{~d}$ of life. Venous blood was obtained from groups of at least five rats at various ages for determination of hematocrit (L/L) and reticulocytes (percentage). Mean values are represented by open circles and SEM is represented by the bracket.

in the epo recipients than in the controls. No consistent changes were observed in the circulating concentrations of neutrophils, monocytes, or lymphocytes.

Effect of epo administration on marrow and splenic erythroid and granulocytic cells. The absolute number of NSP cells, NPP cells, and normoblasts from the spleens and marrows of animals injected with epo versus control animals are shown in Table 2. Although the absolute number of normoblasts increased in spleens and marrows, no change in the number of either postmitotic or immature neutrophils was observed.

Effect of epo administration on erythroid and granulocytic progenitors. The upper panel of Figure 3 shows the effect of increasing the concentration of epo, in vitro, on generation of CFU-E colonies from the marrow of 8- to 9-d-old rats. Because epo concentrations of $0.25 \mathrm{IU} / \mathrm{mL}$ resulted in plateau CFU-E colony generation, this concentration was used in subsequent CFU-E studies. The lower panel of Figure 3 shows the effect of increasing the concentrations of SCM on generation of CFUGM colonies from marrow of 8- to 9-d-old rats. SCM concentrations of $10 \%$ resulted in plateau CFU-GM colony formation, and this concentration was used in subsequent studies.

The absolute number of CFU-E, CFU-GM, BFU-E, and CFUMIX colonies in the total skeletal marrow of animals injected with either epo or control are shown in Table 3. CFU-E colonies increased by approximately 4-fold in the epo recipients, but no effect was seen on the number of CFU-GM, BFU-E, or CFUMIX colonies. 
Table 1. In vitro effect of increasing concentrations of epo on generation of CFU-GM colonies, neutrophils, macrophages, undifferentiated blasts, and normoblasts*

\begin{tabular}{|c|c|c|c|c|c|}
\hline \multirow[b]{2}{*}{ [Epo] } & \multirow{2}{*}{$\begin{array}{c}\text { CFU-GM/ } \\
10^{4} \\
\text { Cells Plated } \dagger\end{array}$} & \multirow[b]{2}{*}{ Neut } & \multicolumn{2}{|c|}{ Cells generated $/ 10^{3}$ cells plated } & \multirow[b]{2}{*}{ Normo } \\
\hline & & & $\mathrm{Mac}$ & Blast & \\
\hline 0 & $24.2 \pm 4.1 \neq$ & $87200 \pm 800$ & $126800 \pm 10200$ & $68300 \pm 2600$ & 0 \\
\hline 0.1 & $19.0 \pm 2.2$ & $105700 \pm 7100$ & $75700 \pm 4200 \S$ & $75800 \pm 16300$ & $14300 \pm 4800$ \\
\hline 1.0 & $16.6 \pm 1.2$ & $81100 \pm 5100$ & $90600 \pm 15200$ & $43700 \pm 1800$ & $22700 \pm 1800$ \\
\hline 10.0 & $12.0 \pm 1.8$ & $53300 \pm 9200 \S$ & $118800 \pm 15500$ & $63700 \pm 11700$ & $51200 \pm 10400 \|$ \\
\hline Inact epo & $22.4 \pm 2.7 末$ & $83000 \pm 7000$ & $104900 \pm 8900$ & $56100 \pm 4700$ & 0 \\
\hline
\end{tabular}

* CFU-GM colonies that developed in plates to which various concentrations of epo were added are expressed as colonies per $10^{4}$ cells plated. The number of neutrophils, macrophages, undifferentiated blasts, and normoblasts washed from these plates are expressed as cells per $10^{3}$ cells plated. Abbreviations: [Epo], concentration of epo IU/mL; Neut, neutrophils; Mac, macrophages; Blast, undifferentiated blasts; Normo, normoblasts; Inact epo, $4 \mathrm{IU}$ epo/mL which had been preneutralized by incubation with antiepo antiserum.

$\dagger$ Mean \pm SEM of three experiments, each using quadruplicate culture plates.

$\ddagger p<0.03$ vs $10.0 \mathrm{IU} \mathrm{epo} / \mathrm{mL}$.

$\S p<0.01$ vs 0 epo.

$\| p<0.02$ vs $0.1 \mathrm{IU}$ epo $/ \mathrm{mL}$.
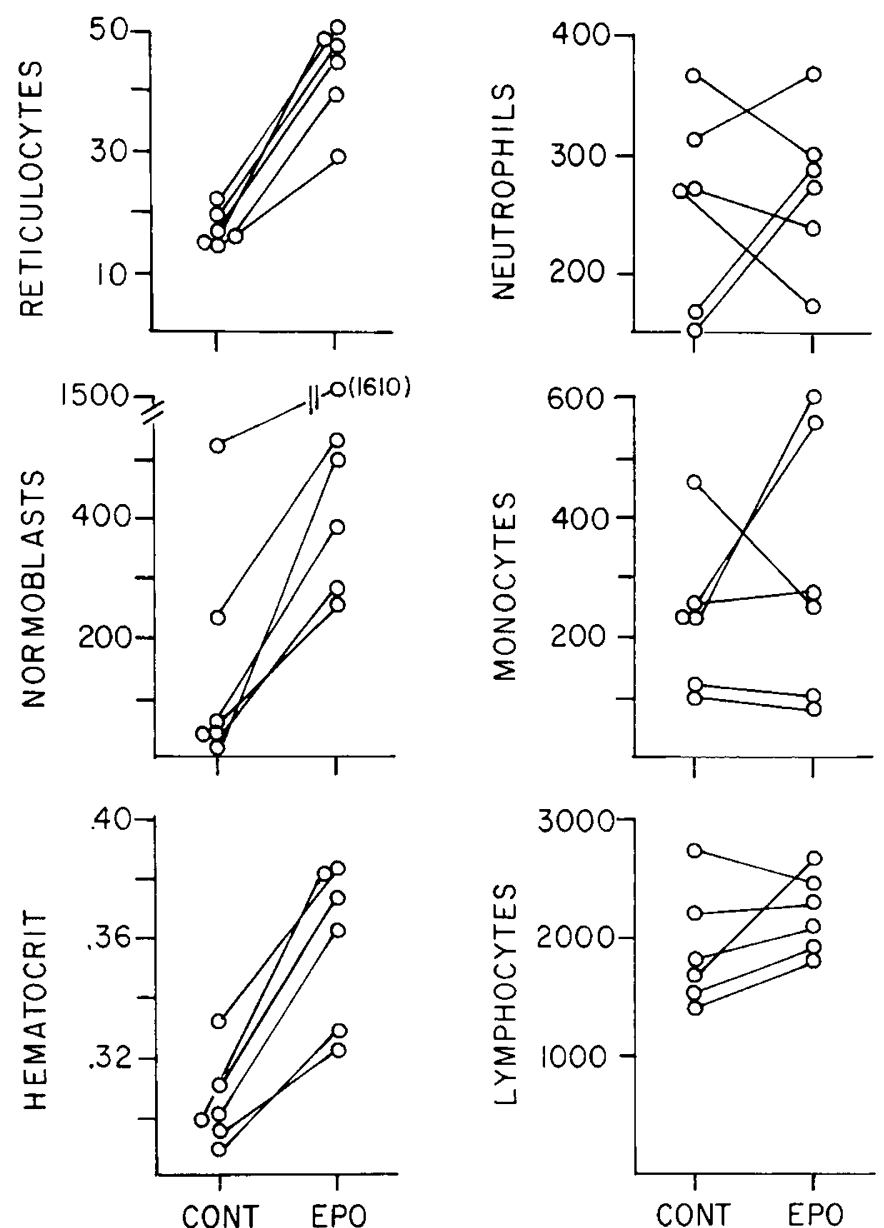

Fig. 2. Blood concentrations of erythrocytes, reticulocytes, normoblasts, neutrophils, monocytes, and lymphocytes in pairs of weanling rats treated for $3 \mathrm{~d}$ with either epo or a control. CONT, Control; EPO, erythropoietin. Six experiments were performed in which one rat was injected with epo while a littermate was injected with a control. Fortyeight $\mathrm{h}$ after three daily injections, animals were killed and venous blood was obtained for reticulocytes (percent), normoblasts (cells $/ \mathrm{mm}^{3}$ ), hematocrits $(\mathrm{L} / \mathrm{L})$, neutrophils (cells $\left./ \mathrm{mm}^{3}\right)$, monocytes (cells $/ \mathrm{mm}^{3}$ ), and lymphocytes $\left(\right.$ cells $/ \mathrm{mm}^{3}$ ). The individual values are given by open circles, and paired values are connected by lines.

\section{DISCUSSION}

Epo is a hormone synthesized by peritubular renal cells (21) and reticuloendothelial cells (22) in response to hypoxia. The human gene for epo has been cloned $(23,24)$ and sequenced (25), and recombinant epo has been administered to humans affected with hyporegenerative anemia secondary to defective epo production $(6-8,10,26)$. Early studies cautioned that administration of epo to humans might result in neutropenia or thrombocytopenia by diversion of multipotent progenitors into erthrocytic maturation at the expense of granulocytic and megakaryocytic production (27). The basis for this concern included the observation of Van Zant and Goldwasser (28) that, in vitro, increasing concentrations of epo resulted in a stepwise reduction in CFU-GM colony formation. In vivo observations also suggested that epo administration might reduce neutrophil production. Specifically, Bradley et al. (29) observed that the accelerated erythropoiesis in mice made anemic by repeated phlebotomy was associated with diminished CFU-GM colony formation, but that a reduction in erythropoiesis after repeated transfusions resulted in increased numbers of CFU-GM colonies. Hellman and Grate (30) observed a smaller than normal neutrophil reserve in mice with accelerated erythropoiesis, and a larger reserve in mice with diminished erythropoiesis. Despite these observations, neither neutropenia nor diminished concentrations of CFU-GM colonies in the marrow have been observed in human adults treated with recombinant epo in doses up to 500 $\mathrm{IU} / \mathrm{kg}$ three times per wk (31).

We have recently observed that fetal progenitors in culture are considerably more sensitive to down-modulation of neutrophil production by epo than are progenitors from adult marrow (12). The mechanism for the epo-induced diminution in fetal neutrophil production includes: 1) a diversion of a group of early clones, which would have otherwise developed into CFU-GM, into normoblast-containing colonies; 2) reduced survival of some of the CFU-GM exposed to high concentrations of epo; and 3) a diminished number of neutrophils in the surviving CFU-GM exposed to high concentrations of epo.

Our studies were undertaken to evaluate the effect of epo administration on neutrophil pool sizes and production using a weanling rat model. In vitro, high concentrations of epo reduced CFU-GM colony formation, similar to that observed in studies of human fetal progenitors $(11,12)$. Although epo caused a significant diminution in the numbers of neutrophils generated, there appeared to be little overall effect on macrophage generation. In vivo, epo resulted in accelerated erythropoiesis. However, no alterations were observed in the circulating concentrations of neutrophils nor in the sizes of the NSP, NPP, or granulocytic progenitor pools. 
Table 2. Quantitation of splenic and bone marrow neutrophilic and erythroid cells in weanling rats after three daily injections of epo or control*

\begin{tabular}{|c|c|c|c|c|c|c|}
\hline & \multicolumn{3}{|c|}{ Spleen } & \multicolumn{3}{|c|}{ Marrow } \\
\hline & \multicolumn{3}{|c|}{ NPP } & \multicolumn{3}{|c|}{ NPP } \\
\hline & NSP & $\left(\right.$ Cells $\left.\times 10^{-6}\right)$ & Normo & NSP & $\left(\right.$ Cells $\left.\times 10^{-6}\right)$ & Normo \\
\hline Control & $4.9 \pm 1.0$ & $1.0 \pm 0.3$ & $37.5 \pm 3.5$ & $35.4 \pm 6.1$ & $7.1 \pm 3.8$ & $100.8 \pm 11.3$ \\
\hline Epo & $7.3 \pm 0.7$ & $3.1 \pm 1.2$ & $84.9 \pm 6.5 \dagger$ & $50.9 \pm 14.0$ & $14.5 \pm 7.5$ & $297.8 \pm 42.0 \dagger$ \\
\hline
\end{tabular}

* NSP, segmented neutrophils + band neutrophils + metamyelocytes; NPP, myelocytes + promyelocytes + myeloblasts; Normo, normoblasts. $\dagger p<0.001$ vs control.

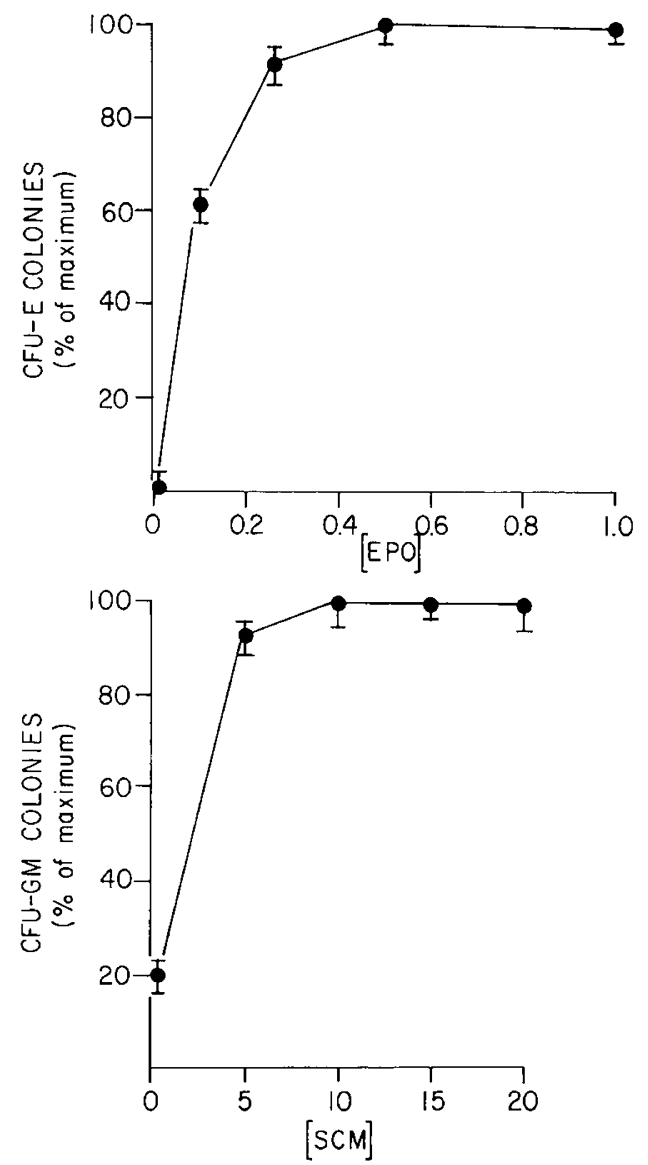

Fig. 3. The effect of increasing concentrations of epo on CFU-E generation, and SCM on CFU-GM generation. EPO, erythropoietin; SCM, pokeweed mitogen-stimulated, spleen-cell conditioned medium. CFU-E colonies that developed in various concentrations of EPO and CFU-GM colonies that developed in various concentrations SCM are shown. Mean values are represented by solid circles and the brackets represent SEM.

Table 3. Quantitation of hematopoietic progenitors in groups of weanling rats treated for 3-d with epo or control

\begin{tabular}{lcrrr}
\hline & \multicolumn{4}{c}{ Progenitors/marrow $\left(\text { cells } \times 10^{-3}\right)^{*}$} \\
\cline { 2 - 5 } & CFU-E & CFU-GM & \multicolumn{1}{c}{ BFU-E } & CFU-MIX \\
\hline Control & $299.3 \pm 16.1$ & $178.5 \pm 14.4$ & $10.5 \pm 3.5$ & $19.3 \pm 3.3$ \\
Epo & $1337.1 \pm 99.1 \dagger$ & $174.8 \pm 23.4$ & $8.3 \pm 5.0$ & $13.4 \pm 2.8$ \\
\hline
\end{tabular}

* The number of progenitors in the entire skeletal marrow was extrapolated from the number of cells flushed from the combined femurs and the frequency of colonies generated in culture.

$\dagger p<0.001$ vs control.
The discrepancy between the effects of epo on neutrophil production in vitro and in vivo cannot be explained by our studies. It is possible that, despite dosages of $2000 \mathrm{IU} / \mathrm{kg}$, the concentrations of epo achieved in vivo in the marrow microenvironment are not comparable to those required to achieve downmodulation of neutrophil generation in vitro. Alternatively, it may be that the relationship between epo and granulocytopoiesis in culture fails to reflect the complex interactions between hematopoietic progenitors and growth factors in vivo $(32,33)$. Despite our lack of evidence of down-modulation of granulocytopoiesis by epo administration to weanling rats, we suggest that neutrophil production be monitored in clinical trials of epo administration to anemic neonates.

\section{REFERENCES}

1. Spivak JL 1986 The mechanism of action of erythropoietin. Int J Cell Cloning 4:139-166

2. Zanjani ED, Ascensao JL 1989 Erythropoietin. Transfusion 29:46-57

3. Stockman III JA, Graeber J, Clark DA, McClellan K, Garcia JF, Kavey REW 1984 Anemia of prematurity: determinants of the erythropoietin response. J Pediatr 105:786-792

4. Shannon KM, Naylor GS, Torkilson JC 1987 Circulating erythroid progenitors in the anemia of prematurity. N Engl J Med 317:728-733

5. Rhondeau SM, Christensen RD, Ross MP, Rothstein G, Simmons MA 1987 Responsiveness of marrow erythroid progenitors from infants with the "anemia of prematurity" to recombinant human erythropoietin. J Pediatr 112:935-940

6. Eschbach JW, Egrie JC, Downing MR, Browne JK, Adamson JW 1987 Correction of the anemia of end-stage renal disease with recombinant human erythropoietin: results of a combined phase I and II trial. N Engl J Med 316:73-78

7. Winearls CG, Pippard MJ, Downing M, Oliver DO, Reid C, Cotes PM 1986 Effect of human erythropoietin derived from recombinant DNA on the anaemia of patients maintained by chronic haemodialysis. Lancet 2:11751178

8. Adamson JW, Egrie JC, Browne JK, Downing MR, Eschbach W 1988 The use of recombinant human erythropoietin (EPO) to correct the anemia of end-stage renal disease: a progress report. Behring Inst Mitt 83:188-192

9. Stockman III JA 1988 Erythropoietin: off again, on again. J Pediatr 112:906908

10. Moia M, Mannuci PM, Vizzotto L, Casati S, Cattaneo M, Ponticelli C 1987 Improvement in hemostatic defect of uremia after treatment with recombinant human erythropoietin. Lancet 2:1227-1229

11. Migliaccio AR, Migliaccio G 1988 Human embryonic hemopoiesis: control mechanisms underlying progenitor differentiation in vitro. Dev Biol 125:127-134

12. Christensen RD, Koenig JM, Viskochil D, Rothstein G 1989 Down-modulation of neutrophil production by erythropoietin in human hematopoietic clones. Blood 74:817-822

13. Hill HR 1987 Biochemical, structural, and functional abnormalities of polymorphonuclear leukocytes in the neonate. Pediatr Res 22:375-382

14. Christensen RD, Macfarlane JL, Taylor NL, Hill HR, Rothstein G 1982 Blood and marrow neutrophils during experimental group B streptococcal infection: quantification of the stem cell, proliferative, storage and circulating pools. Pediatr Res 16:549-553

15. Erdman SH, Christensen RD, Bradley PP, Rothstein G 1982 Supply and release of storage neutrophils: a developmental study. Biol Neonate 41:132137

16. Parker JW, Metcalf D 1974 Production of colony-stimulating factor in mitogen-stimulated lymphocyte cultures. J Immunol 112:502-510

17. Nakahata T, Ogawa M 1982 Clonal origin of murine hemopoietic colonies with apparent restriction to granulocyte-macrophage-megakaryocyte differentiation. J Cell Physiol 111:239-246

18. Krystal G, Eaves CJ, Cashman J 1989 HCC-3 rabbit anti-erythropoietin antiserum. Proc Natl Acad Sci USA (in press)

19. Kimura H, Finch CA, Adamson JW 1986 Hematopoiesis in the rat: quantification of hematopoietic progenitors and the response to iron deficiency anemia. J Cell Physiol 126:298-306 
20. Hara H, Ogawa M 1978 Murine hemopoietic colonies in culture containing normoblasts, macrophages and megakaryocytes. Am J Hematol 4:23-34

21. Lacombe C, Da Silva JL, Bruneval P, Fournier JG, Wendling F, Casadevale $\mathrm{N}$, Camilleri J-P, Bariety J, Varet B, Tambourin P 1988 Peritubular cells are the site of erythropoietin synthesis in the murine hypoxic kidney. J Clin Invest 81:620-623

22. Goldberg MA, Dunning SP, Bunn HF 1988 Regulation of the erythropoietin gene: evidence that the oxygen sensor is a heme protein. Science 242:14121415

23. Jacobs K, Shoemaker C, Rudersdorf R, Neill SD, Kaufman RJ, Mufson A Seehra J, Simon SJ, Hewick R, Fritsch EF, Kawakita M, Shimizu T, Miyake 1985 Isolation and characterization of genomic cDNA clones of human erythropoietin. Nature 313:806-810

24. Lin FK, Suggs $\mathrm{S}$, Lin CH, Browne JK, Smalling R, Egrie JC, Chen KK, Fox GM, Martin F, Stabinsky Z, Badrawis M, Lai PH, Goldwasser E 198 Cloning and expression of the human erythropoietin gene. Proc Natl Acad Sci USA 82:7580-7584

25. MacDonald ID, Lin FK, Goldwasser E 1986 Cloning sequencing and evolutionary analysis of the mouse erythropoietin gene. Mol Cell Biol 6:842-848
26. Steward WP, Scarffe JH 1989 Clinical trials with haematopoietic growth factors. Prog Growth Factor Res 1:1-12

27. Metcalf D 1988 Haematopoietic growth factors. Med J Aust 148:516-519

28. Van Zant G, Goldwasser E 1977 Simultaneous effect of erythropoietin and colony-stimulating factor on bone marrow cells. Science 198:733-735

29. Bradley TR, Robinson W, Metcalf D 1967 Colony production in vitro by normal, polycythemic, and anaemic bone marrow. Nature 214:511-512

30. Hellman S, Grate HE 1967 Haematopoietic stem cells: evidence for competing proliferative demands. Nature 216:65-66

31. Stone WJ, Graber SE, Krants SB, Dessypris WN, O'Neill VL, Olson NJ, Pincus TP 1988 Treatment of the anemia of predialysis patients with recombinant human erythropoietin: a randomized, placebo-controlled trial. Am J Med Sci 296:171-179

32. Walker F, Nicola NA, Metcalf D, Burgess AW 1985 Hierarchical downmodulation of hematopoietic growth factor receptors. Cell 43:269-276

33. Nicola NA, Vadas MA, Lopez AF 1986 Down-modulation of receptors for granulocyte colony-stimulating factor on human neutrophils by granulocyteactivating agents. J Cell Physiol 128:501-509 